\title{
Codeine-Induced Syndrome of Inappropriate Antidiuretic Hormone: Case Report
}

\author{
Samet Karahan, Hatice Karagöz, Abdulsamet Erden, Deniz Avcı, Kübra Esmeray
}

Department of Internal Medicine, Kayseri Training and Research Hospital, Kayseri, Turkey

Background: The syndrome of inappropriate antidiuretic hormone was first described in 1957 by Schwartz, and is characterised by hyponatraemia, inappropriately increased urine osmolality and urine sodium, and decreased serum osmolality in a euvolemic patient without edema. A patient with the syndrome of inappropriate antidiuretic hormone should have normal cardiac, renal, adrenal, hepatic, and thyroid functions and should not take any diuretics.

Case Report: We present a case of the syndrome of inappropriate antidiuretic hormone caused by codeine and associated with reduced urine volume, increased urine sodium, and decreased serum sodium concentration.

Conclusion: The syndrome of inappropriate antidiuretic hormone is a disease that can lead to morbidity and even mortality. Clinicians should measure serum electrolytes intermittently in order to avoid missing the diagnosis of the syndrome of inappropriate antidiuretic hormone in patients using opioid. (Balkan Med J 2014;31:107-109).

Key Words: Arginine vasopressin, codeine phospate, GABA agents, hyponatraemia, inappropriate ADH syndrome
The syndrome of inappropriate antidiuretic hormone (SIADH) was first described in 1957 by Schwartz and colleagues in two lung cancer cases that showed urinary sodium loss (1). SIADH is characterised by hyponatraemia, inappropriately increased urine osmolality, increased urine sodium, and decreased serum osmolality in a euvolemic patient without edema. Also, these findings should be considered in a patient with normal cardiac, renal, adrenal, hepatic, and thyroid functions and taking no diuretics. Excess water is the main problem in SIADH and therefore dilutional hyponatraemia develops (2).

Codeine is an opioid analgesic used for moderate to severe pain. Its analgesic effect is dependent on the conversion to morphine and morphine-6-glucuronide because the binding affinity of codeine to $\mu(\mathrm{mu})$ opioid receptors is 200 -fold less than that of morphine (3). Constipation and lethargy are frequent side effects. The side effect profile, such as nausea, vomiting, hypotension, tachycardia-bradycardia, confusion, imbalance, headache, dizziness, fatigue, urticaria, ureteral spasm, reduction in miction, and the very rarely seen tonicclonic seizures and respiratory depression is quite wide (4). However, some of the symptoms observed during the use of codeine such as nausea, vomiting, headache, fatigue, confusion, and seizures can also be the symptoms of hyponatraemia. In this case report, we present a SIADH patient with reduced urine volume, increased urine sodium, and decreased serum sodium concentration after using codeine-paracetamol combination medication, which is rarely encountered before, according to our review of the literature.

\section{CASE PRESENTATION}

A previously healthy 77-year-old female of $82 \mathrm{~kg}$ in weight and $161 \mathrm{~cm}$ in height presented to the emergency service with a 3 to 4 day history of reduced amount of urine, nausea, vomiting, weakness, anorexia, dizziness, abdominal pain, constipation, and abdominal bloating. Fifteen days ago, she was admitted to the dermatology clinic for the vesicular and painful lesions on the right middle of the abdomen. She was prescribed hydroxyzine $25 \mathrm{mg}$ tablets, topical mupirocin pomade, flurbiprofen tablets, and a combination of vitamin B1 and B6 pills for the diagnosis of herpes zoster; however, she used these medications only once because her pain was not resolved. After that, she used the combination of codeine phosphate $30 \mathrm{mg}$ and paracetamol $500 \mathrm{mg}$, which is unused in our country and was brought by her son from abroad, for her painful lesions.

On physical examination, the patient showed full cooperation and orientation. Her vital signs were as follows: temperature $36.6^{\circ} \mathrm{C}$, heart rate: $102 /$ minute, respiratory rate: 18/minute, and blood pressure: 107/82 mmHg. Her mucous membranes were wet; turgor and tonus were normal. She had 
bilateral breath sounds, and no rales and rhonchi were heard. Heart sounds were normal except for mild tachycardia (102/ minute). Examination of the abdomen revealed vesicular lesions extending from the umbilicus to the waist on a single dermatome zone and some of the lesions were resolving. She had hypoactive bowel sounds. There was no hepatosplenomegaly, peripheral lymphadenopathy, or pretibial edema. Laboratory investigations on admission were as follows: BUN, 24 $\mathrm{mg} / \mathrm{dL}$; creatinine, $1.0 \mathrm{mg} / \mathrm{dL}$; AST, $17 \mathrm{U} / \mathrm{L}$; ALT, $18 \mathrm{U} / \mathrm{L}$; $\mathrm{Na}, 112 \mathrm{mmol} / \mathrm{L}$; and $\mathrm{K}, 4.1 \mathrm{mmol} / \mathrm{L}$. Other biochemical parameters were normal. Hepatitis markers and anti-HIV serology were negative. Thyroid function tests, ECG, and echocardiography were performed for the etiology of euvolemic hyponatraemia and these were all normal. ADH measurement cannot be performed in our hospital, so serum ADH level was not measured.

The patient was normotensive and hyperkalaemia and hypoglycaemia were not observed, so adrenal insufficiency was excluded. She was euvolemic and did not use a diuretic drug or combination. The patient's serum sodium concentration was $112 \mathrm{mmol} / \mathrm{L}(135-145 \mathrm{mmol} / \mathrm{L})$, serum osmolarity was $238 \mathrm{mOsm} / \mathrm{L}(275-295 \mathrm{mOsm} / \mathrm{L})$, urine sodium concentration was $55 \mathrm{mmol} / \mathrm{L}(<20 \mathrm{mmol} / \mathrm{L})$, and urine osmolality was 452 $\operatorname{mosm} / \mathrm{kg}$, so she was diagnosed as SIADH. Other conditions that may lead to SIADH such as lung cancer and cranial pathologies were excluded by chest radiography and cranial tomography. Sodium deficit was calculated as $885 \mathrm{mEq}$. After administiration of $250 \mathrm{cc} 3 \%$ saline infusion in 5 hours, the symptoms of vomiting, weakness, and dizzines disappeared. After limitation of water and interruption of drugs, serum $\mathrm{Na}$ concentration rose to $137 \mathrm{mmol} / \mathrm{L}$ in 72 hours and the patient was diagnosed as SIADH due to codeine usage.

\section{DISCUSSION}

Codeine is a natural derivative of opium alkaloids. Besides its relatively weak analgesic effect, it is used as an antitussive and antidiarrhoeal drug. It is a less effective analgesic than the other non-steroidal drugs, tramadol, and even paracetamol (5). It exerts its analgesic effect by its conversion to morphine and morphine-6-glucuronide in the liver. Codeine is bioactivated to morphine and morphine-6-glucuronide by the hepatic cytochrome P4502D6 (CYP2D6). Therefore, as an analgesic, the efficacy and safety of codeine are very closely related to CYP2D6 polymorphism. It is known that codeine has lower activity in patients who are CYP2D6 poor metabolisers but the toxicity risk of morphine is higher in patients who metabolise ultrafast (6).

SIADH is a syndrome characterised by low serum sodium level, low serum osmolality, high urine osmolality, and high urine sodium in the situation that arginine-vasopressin secre- tion from the posterior pituitary must be blocked but continues. There are many reasons for SIADH but the pathophysiology of the arginine-vasopressin secretion cannot be elucidated in the majority of SIADH patients due to drug use (7). In our patient, we observed codeine-induced SIADH, which is rarely encountered.

SIADH can be caused by a variety of drugs, particularly carbamazepine, selective seratonin reuptake inhibitors (SSRIs), and phenothiazines. Many cases and clinical investigations have documanted that SSRIs can significantly cause hyponatraemia. Opioids act centrally via $\mu$ receptors, providing moderate to severe pain relief. Opioids also inhibit the reuptake of neurotransmitters, such as noradrenaline (norepinephrine) and serotonin most prominently. Based on this information, Udy and colleagues presented a case of tramadol-induced hyponatraemia after unicompartmental knee replacement surgery (8).

It is known that all opioids exert their effects by interacting with $\mu$ opioid receptors involved in the pain warning of the central nervous system, which are located both presynaptically and postsynaptically (9). As a result of stimulation of the presynaptic $\mu$ receptors, the release of $\gamma$-amino butyric acid (GABA), an inhibitor neurotransmitter, is inhibited and inhibition of the dopamine pathways is increased (10). It is known that GABA is the major inhibitor neurotransmitter in the central nervous system and also in the hypothalamic neural axis. Therefore, as a result of stimulation of presynaptic $\mu$ receptors by morphine, the secretion of inhibitor neurotransmitter GABA is blocked and arginine-vasopressin secretion increases. Also, codeine may inhibit the reuptake of serotonin and noradrenaline-like SSRIs. We think that in our patient, arginine-vasopressin secretion might have been increased by such mechanisms and so SIADH developed. Our patient was treated by $3 \%$ saline infusion, fluid restriction, and discontinuation of drug therapy and her serum sodium returned to normal levels on the third day. We know that pain caused by shingles may increase AVP secretion from the pituitary gland or its effect at the collecting duct, which then cause hyponatraemia itself. However, the patient's pain persisted even when her sodium was normalised and discontinuation of her medication is the major therapeutic argument. Thus, we do not think the pain caused by herpes zoster was the cause of SIADH. As a result, clinicians should measure serum electrolytes intermittently in order to avoid missing the diagnosis of SIADH in patients using opioid analgesics.

Ethics Committee Approval: Ethics committee approval was received for this report.

Informed Consent: Written informed consent was obtained from the participants of this study.

Peer-review: Externally peer-reviewed. 
Author contributions: Concept - S.K.; Design - A.E.; Supervision - H.K.; Resource - D.A.; Materials - S.K.; Data Collection\&/or Processing - S.K.; Analysis\&/or Interpretation - S.K.; Literature Search - S.K., D.A., K.E.; Writing - S.K.; Critical Reviews - S.K., H.K., A.E.

Conflict of Interest: No conflict of interest was declared by the authors.

Financial Disclosure: The authors declared that this study received no financial support.

\section{REFERENCES}

1. Schwartz WB, Bennett W, Curelop S, Bartter FC. A syndrome of renal sodium loss and hyponatremia probably resulting from inappropriate secretion of antidiuretic hormone. Am J Med 1957;23:529-42. [CrossRef]

2. Miller M. Syndrome of excess antidiuretic hormone release. Crit Care Clin 2001;17:11-23. [CrossRef]

3. Volpe DA, McMahon Tobin GA, Mellon RD, Katki AG, Parker RJ, Colatsky $\mathrm{T}$, et al. Uniform assessment and ranking of opioid Mu receptor binding constants for selected opioid drugs. Regul Toxicol Pharmacol 2011;59:385-90. [CrossRef]
4. Tavassoli N, Lapeyre-Mestre M, Sommet A, Montastruc JL; French Association of Regional Pharmacovigilance Centres. Reporting rate of adverse drug reactions to the French pharmacovigilance system with three step 2 analgesic drugs: dextropropoxyphene, tramadol and codeine (in combination with paracetamol). Br J Clin Pharmacol 2009;68:422-6. [CrossRef]

5. McQuay H, Moore A. An Evidence-Based Resource for Pain Relief. Oxford, UK: Oxford University Press, 1998.

6. Gasche Y, Daali Y, Fathi M, Chiappe A, Cottini S, Dayer P, et al. Codeine intoxication associated with ultrarapid CYP2D6 metabolism. $N$ Engl J Med 2004;351:2827-31. [CrossRef]

7. Ellison DH, Berl T. Clinical practice. The syndrome of inappropriate antidiuresis. N Engl J Med 2007;356:2064-72. [CrossRef]

8. Udy A, Deacy N, Barnes D, Sigston P. Tramadol-induced hyponatraemia following unicompartmental knee replacement surgery. Anaesthesia 2005;60:814-6. [CrossRef]

9. Davis M, Pasternak G. Opioid receptors and opioid pharmacodynamics. In Davis M, Glare P, Hardy J (eds). Opioids in Cancer Pain. Oxford, UK: Oxford University Press, 2005, 11-41.

10. Koneru A, Satyanarayana S, Rizwan S. Endogenous opioids: their physiological role and receptors. Global Journal of Pharmacology 2009;3:149-53. 